\title{
HYBRID FORM OF INTERACTION BETWEEN THE CIVIL SOCIETY AND THE STATE: ANATOMY OF UKRAINIAN CYCLICAL CRISIS
}

\author{
O. Onufrienko ${ }^{1}$
}

DOI: http://doi.org/10.15350/L_26/8/08

\begin{abstract}
Proposed paper analyzes common and distinctive features of the concepts of historic recurrence in social sciences and philosophy; complex nature of Ukrainian cyclical social crisis has been described. We proceed from the fact that processes of recurrent multiple-aspect convergence and divergence should be referred to fundamental forms of dialectic interaction between the civil society and the state. Such an approach enables to outline and differentiate convergent (stable democracy), divergent (authoritarian state) and hybrid forms of interaction. Mixed or hybrid democratic societies (modern Ukraine should be attributed hereinto) are the result of differently directed interaction between institutions of civil society and bodies of public administration. It has been proved that the essence of the cyclical recurrent crisis in Ukraine is foremost predetermined by the failure to implement the convergent model of the interaction between state administration bodies and civil society. As a result, it can't be resolved only by means of system reforms for public administration (even the successful ones) or by means of favoring the civil society development. It is necessary to make conscious efforts to implement the convergent form of the interaction between civil society and the state at all its levels: teleological, institutional, axiological, instrumental ones, etc. The situation is only going to get worse due to the attempts to impose to a polarized society inherently apt to 'pendular' oscillations the linear development model that is often reduced to the perception of single values and joining certain political community. Social transformation strategies in Ukraine should take into account the cyclic character of the interaction between state administration bodies and civil society and foresee, first of all, the minimization of negative effects of a cyclical recurrent crisis. The elaboration of such strategies seems to be possible within the context of wide range of social sciences.
\end{abstract}

Keywords: social sciences, public administration, interaction between the State and civil society, concepts of recurrence, repetition of social phenomena, cyclical crisis.

${ }^{1}$ Oleksiy Onufrienko, Ph.D. in Law, Associate Professor, Doctoral Candidate of the Department of Public Administration and Local Self-Administration of Dnipropetrovs'k Regional Institute of Public Administration of the National Academy of Public Administration under the President of Ukraine. 


\section{Concepts of historic recurrence in philosophy and social sciences}

Cyclical theories found in modern philosophy and within a wide range of social sciences are most fundamentally represented in social, political and especially in economic sciences. The fact of available economic cycles and periodic crises in capitalist economy is definitely beyond doubt; and the problem of prevention and minimization of economic system losses during a recurrent crisis is in the foreground of both high priority researches and a state policy in developed countries There is no occasion to disagree with the scientists who believe that the emergence of cyclical theories is chiefly provided by the attempts to understand typologically similar phases of social process development and subject them to a comparative analysis [12, p. 7]. It is noteworthy that such motivation is completely relevant to ideas stated as early as in the time of antiquity. Though modern concepts are based on a fundamentally different methodological basis, they use a statistical data bulk (including a world-wild scale), have the possibility to critically evaluate the results of applying the linear models suggested within the positivism studies, pay particular attention to revealing the objective factors that provide the historic recurrence and usually refrain from drawing conclusions on the availability of strictly predetermined succession of events in social life.

The experience of surveillance over the phenomenon of the Ukrainian social transformations recurrence when the rising phase shall inevitably terminates the coming-out phase into a new typical crisis mostly presented in political and economic spheres, enables to affirm that it is challenging to research effective procedures to diminish negative consequences of system social crises on a recurrent basis and in prospect to research effective procedures of stating the proven concepts of historic recurrence within public administration studies.

Comprehending the above-mentioned made it possible to set a relevant complex goal of the paper suggested, namely: to make an integrative analysis of developing concepts of historic recurrence in philosophy and social science; evaluate the scientific substantiation of the most substantial modern approaches, describe the essence of different kinds of cycles as the phenomenon of a social life and describe the recurrent aspects of an interaction between the state and civil society basing on the experience of surveillance over social transformations and recurrent crisis phenomena in independent Ukraine, outline the prospects for further subject public administration researches.

The doctrine development of concepts of historic recurrence has taken a long time. It is appropriate to mention the works of prominent antique philosophers Plato, Aristotle, Polybius, Cicero as well as thinkers of the Modern era: N. Machiavelli and G. Vico. A great contribution was made by O. Spengler and A. Toynbee, P. Sorokin, N. Kondratiev and J. Schumpeter. The subject-matter problems attract continuous attention of contemporary researchers' who represented full range of social sciences: fundamental researches were set out by A. Korotaev, A. Medushevskiy, Yu. Plotinskiy. Different aspects of historic recurrence within the research of a complex interaction between the state and civil society are being considered by the Ukrainian public administration scholars: 0 . Aleinikova, V. Aleksieiev, I. Pysmennyi, O. Pukhkalo, S. Seriohin. 
The phenomenological character of modern approaches to understanding recurrence of social transformation is predetermined by the authors' confidence in existence of recurrent transformation of the social reality as the phenomena presented in sensual observation. The cycle (from the Greek kyklos 'circle') is total phenomena, processes that provide recurrence over a definite period of time and brings the system into outgoing state or similar to outgoing state [16]. Cyclical theories (the concepts of historic recurrence) are the concepts of social development characterized by such a determining feature as the idea of continuous and regular passing through equivalent cycles by different social formations, that is a motion through sequentially related phases (crisis, depression, revival, boom) [12, p. 11].

The idea of historic recurrence is well-known in many cultures. Historic recurrence conception was most consequently developed by the ancient philosophers mainly within the framework of problems of incremental changes in the forms of government. Plato emphasized that an alternation of catastrophes and birth are characteristic of cosmos and inherent cycles are specific to any society [16]. The notion of historic recurrence is fundamental one in the philosophy of Plato: "Now God alternately guides the motion of the universe himself providing its circular motion, then He gives rein when the universe recurrence tends to cause the appropriate proportionality in time; then this motion is spontaneously reversed" [19, p. 27]. Plato's concept of historic recurrence enabled him - within the framework of political philosophy only - divide social and political forms of government into ideal and real ones with this cyclic development intrinsic to the latter. The philosopher considered the problem of historic recurrence in forms of government influenced by the society and put forward the problem of a need to search the mechanism able to prevent regressive tendencies to recurrent transformations (he found the problem solution in the development of universal harsh laws and concentration of power in hands of the particular elite) [12, p. 12-13].

Aristotle used the concept of historic recurrence in his personal approach to comprehend the character of nature motion ("circular motion") [3, p. 309] and the interaction of opposites, as well as he drew a conclusion about historic recurrence of political life phenomena [12, p. 14]. According to Aristotle the true forms of government (monarchy, aristocracy, politeia) degenerate into perverted ones (respectively tyranny, oligarchy, ochlocracy), but non-effective form is transformed into effective one at a new stage of cyclic development (monarchy degrades into tyranny, but tyranny turns into aristocracy etc.). Aristotle as well as Plato came to the conclusion that historic recurrence of such transformation was unfavourable and suggested a mixed form as to be the most reliable.

Further improvement of the theory of historic recurrence in forms of government was suggested by Cicero who considered the dynamic of changes in the political system as the change in social forms that conventionally vary between extreme range models thus providing a continuous change both political elites but the forms of government. According to Cicero the wise rule's task is to foresee the cyclic transformations and deliberate influence on them if necessary to hinder the processes or impede them [12, p. 14]. 
An appreciable contribution to the development of the ancient theory of historic recurrence of constitutions (political systems) of was made by Polybius. Polybius believes that historic recurrence of alterations and unavoidable changes of forms of government run their natural course in line with social transformations. True forms are transformed into perverted ones when political elites or even the society degrade; when the perverted form becomes intolerable, the society recovers a new true system caused by the revolution etc. This is the manner in which the initial stages (monarchy) is transformed into the authority of kings that degrade into tyranny that one is changed for aristocracy that is converted into oligarchy. Oligarchy is changed for democracy that generates into ochlocracy; the only withdrawal from the anarchy chaos is to return to monarchy [5, pp. 3-4] and going into a new cycle. Moreover, every system also passes through its own developing cycle - genesis, growth, peak, change (turn), end [5, pp. 3-4]. Despite the fact that antiquity study does not provide single approach to understanding historic recurrence of political systems according to Polybius (the place of original monarchy is a vexed question: some researchers consider it separately as an initial primitive state existing prior to the beginning of cyclical transformations [5, pp. 4-8], the recurrent character of this theory is evident.

After a forced break in the Middle Ages (the historic recurrence did not correspond to theological providentialist understanding of the history), the ancient contribution became an essential background for the concepts of recurrent development suggested in the Early Modern Period and at least partially inspired by fundamental social changes (the Reformation, the English revolution, the colonization of the New World etc.). N. Machiavelli updated ideas of historical recurrence to substantiate his theory of successive change in forms of government [10], [11]. G. Vico who is credited with the philosophy of history proposed a wide concept of a historic recurrence [25].

Modern history is characterized by paying scientific attention to the continuing problem of recurrent development both at the philosophical level and within the framework of social sciences, primarily in economics, politology and sociology firmly established at that time. In particular, historic recurrence finds its specific interpretation in 0. Spengler's works who outlined eight basic cultures as particular social organisms developing from birth to death [20, p. 125]. A. Toynbee proposed the civilization concept (mainly taken from 0 . Spengler's) whereby the world history was considered as a system of local civilizations each of them passes through the recurrence of the same phases of development from birth to death (birth - growth - decline - disintegration [20, p. 127]; the disintegration may result in the birth of new derivative civilizations) producing "a single tree of history". The concept of the authorial intent provided that the genesis and growth of civilizations are determined by the response of the latter to "challenges of the history" (situations of particular problems including foreigners' aggression, the unfavorable weather conditions etc.) and the decline is definitely the consequence of the excessive militarism and tendency to active territorial expansion.

P. Sorokin made a critical survey of concepts of historic recurrence of socio-historical progress for over 100 years and came to the following conclusion: 
the availability of both constantly recurrent identical cycles and stable eternal trends in social changes (emphasis added -0.0.) is not proved; there are grounds to mention only temporary and conventional trends (tendencies) that may be changed for the opposite trend thus producing one of the phases of a long-term cycle [23, pp. 11-12]. If setting aside the much too abstract philosophical concepts and the ambivalent formulae of "socio-cultural life and history may never repeat themselves and, however, in another sense they always repeat themselves to some extent" [24, p. 88] and vast materials research of recurrent changes in different styles of arts in painting, architecture, music etc. [24, pp. 99256], according to P. Sorokin the modification of historical recurrence idea is reduced to the study of "the cyclic and rhythmic recurrences in social phenomena" (author's translation 0.0.) [23, p. 12]. The author found it as one of the chief tasks of sociology on the whole realizing that stating sociological laws and general conclusions, determining the cause-and-effect relationship and making quantitative researches are impossible without the observation over regularly recurrent phenomena of social life [23, p. 12]. These speculations are still topical; according to modern specialists for the recent decades the science of sociology is mainly developing within the framework of paradigms formulated by P. Sorokin.

The life cycle of ethnos was studied by L. Gumilev who outlined seven phases in the change of passionary tension of an ethnic system [20, p. 127-129]. $\mathrm{K}$. Takhtarev proposed the cyclic wave concept of a historical process and singled out five stages on the "evolutionary ladder" (from the epoch of totemism and migrating hunting tribes to the developed class society and the progress of urbanistic civilization) probably founding on the theory of social formations according to K. Marx [9, pp. 58-59].

We believe that it is the development vector stated by P. Sorokin along with a gradual representation of his research results and strengthening their influence on social sciences determined the principal course in the development of subject-matter researches in modern sociology. Hereby, different aspects of recurrent transformation phenomena in social life are analyzed in the context of modern sociology both at macro and micro levels. The development and existence of civil movements are usually studied within the framework of a recurrence concept in particular, 0 . Ramshtad outlined seven phases in the development of civil movement in ideal environment [20, pp. 129-130]; sociologists also research life cycles of an organization, cycles in the development of scientific specialties, analyze the phases of the technology life cycle, consider life cycle of an individual [20, pp. 132-136] etc.

Another significant direction of scientific research of the twentieth century based on the concept of recurrent development as a fundamental principle was established within the economic science. M. Kondratiev and J. Schumpeter were the founders of the theory of economical cycle. Having analyzed vast statistical data bases related to the dynamics of fundamental economic characteristics of developed countries between 1770 and 1926 (indices of commodity prices, interest rates, income, wages and salaries, production output, foreign trade, coal production, gold production etc.) [8, p. 189], M. Kondratiev revealed the so called 
long waves in the world economy. As far back as the early 1920 s of the $20^{\text {th }}$ century he came to the conclusion that the cyclic dynamics in economics reflected periodic displacement from equilibrium, and the phases of major growth cycles were related to the scientific technological revolution or at least they were relevant to the consistent adoption of innovative technology in production and all spheres of life, which stimulated the investment and improved labour productivity [2, p. 5]. J. Schumpeter proposed the concept of economic cycles where the historic recurrence was considered as a regularity of economic growth, and he combined the concepts prior o his research into integrated system identifying long-term cycles, industrial medium-term cycles and minor (money) cycles in the dynamics of economic processes [4, p. 319].

The economic crises, cycle, cyclical crises of national economic systems and world economy are fundamental categories of modern economics. Kondratiev's theory of long waves constantly attracts great attention of academic economists [1] [13] [14] [21]. Economic and financial policy of developed countries provides for fast and adequate response to recurrent crises in capitalist economy even if therewith the traditional liberal principle of limiting government intervention in the economy. Mathematical tools of probability computation that are used (and sometimes to some purpose) in open trade on the interbank foreign exchange market are also developed subject to the cyclical theories. Destructive consequences of the global financial and economic crisis in 2008 increased the scientific interest in the research of the recurrent economic processes. Modern scholarly literature proves among other things that going out into a new systems development phase (and a new great cycle) is possible only under a new scientific technical revolution. Kondratiev's theory of long waves is often taken into consideration in the context of the impact of economic crisis on dynamics of political processes. Hence, fundamental interdisciplinary researches based on applying the data of the whole range of modern social sciences are important today.

Concepts of historical recurrence are widely presented in a political science both at the level of significant theories and at the level of partial concepts that are limited to the analysis of one or several political systems. The former ones are particularly represented by V. Pareto's concept of elite recurrence within the social pyramid, R. Michels's principle of elite theory that is widely known as "iron law of oligarchy" according to which any form of political organization of society sooner or later generates into oligarchy etc. Many partial politological theories were proposed by the US researchers (their origination should be evidently being related to the fact of recurrent "pulsation" of US two-party political system and essential difference in the programmes provided by one governing party or another) [6] [7] [15].

Cyclical theories in one form or another are present in modern jurisprudence. Different aspects of the recurrent dynamics of processes are studied in the mechanism of legal control, algorithmic nature of regulatory legal acts and the specificity of recurrent appliance of legal rules to regulate social relations [17] etc. A. Medushevskiy proposed a fundamental concept of the recurrent development within the framework of the constitutional law. The principal thesis 
of his theory is the availability of constitutional recurrence of different kinds that primarily appears in the recurrence of constitutional development in different countries of the world, in regularities of adopting and making changes in the constitution etc. The author singles out evolutional and revolutionary models of the constitutional recurrence, different models of constitutional cycles in post-socialist countries, evaluates the strategies of withdrawing from these cycles etc. [12].

Finally, the science of public administration mainly presents the problem of recurrence subject to the analysis of the recurrence aspect of applying typical managerial decisions and the study of the state policy directed at recovering from the economic crisis of a recurrent character [2]. Along with this the nonlinearity of social transformations, their wavy nature of specific rhythms and complicated dynamics is distinguished by the Ukrainian leading scientists in public administration as a science, in monographs among others [22].

\section{Hybrid democracy in ukraine: mixed form of interaction between state and civil society \\ Consideration of the peculiar features of Ukrainian social transformations} with their typical successive reinforcement of the opposition between civil society and the state within the complex social crisis that is recurrently repeated, makes it possible to reasonably admit that its prerequisites are primarily formed by differently directed processes under complex dialectics of the interaction between the public administration bodies and institutes of civil society. Understanding thereof puts the subject-matter problem at a peculiar angle of scientific research.

Hereby we proceed from the fact that complex processes of recurrent multiple-aspect convergence and divergence that occur within the institutional, axiological, teleological, instrumental backgrounds should be referred to fundamental forms of dialectic interaction between the civil society and the state (bodies of public administration in the first place) [18, pp. 6-8]. Such an approach enables to outline and differentiate convergent (stable democracy), divergent (authoritarian state) and hybrid forms of interaction. Mixed or hybrid democratic societies (modern Ukraine should be attributed hereinto) are the result of differently directed interaction between institutions of civil society and bodies of public administration. Certainly it is extremely difficult to single out a dominant tendency in these processes, in particular, within little intervals for it is typical of these societies to imitate the required democratic forms to make a positive international reputation, which is associated with the impossibility to provide an efficient interaction between a weak civil society and a non-effective and corrupted state. An institutional convergence may occur, at least, at the level of "rotation" of political parties in the parliament or at the level of transforming civil movements into a political force but the results of political elites changed are usually barely noticeable, actual problems in relations between the society and the state are not solved, divergent processes keep on dominating within the axiological and teleological backgrounds. All this results in the constant recurrence 
of single type cyclical crises; hybrid societies are the least stable in this sense [18, pp. 9-12].

Indeed, despite the whole evident non-identity and different internal and external factors of influence, Ukrainian social transformations (wherein we roughly identify two completed cycles i.e. nineties of the $20^{\text {th }}$ century and 20042013) fully correspond to a typical four-phase structure. The first phase (as a matter of fact, the phase of a system social crisis that is strongly presented in economic and political spheres) is characterized by the failure of inefficient and outdated bodies of public administration to efficiently respond to new complex challenges and quickly turn into forced confrontation of the civil society and the state. The result of the confrontation processes is a partial rotation of political elites that takes place by means of stating simple political slogans that are able to attract interests of the very protesting social part; the declaration of the linear concept of further development, which is usually reduced to the substantiation of a need to adjust a positive foreign experience under reforms and the idea of joining a proper state-political association.

The second phase (depression) is characterized by a gradual extinction of a passionary impulse of a civil society, steep drop for standards of living for the majority of the population and all fundamental economic indices, by a new wave of emigration, the overall degradation of the quality of public administration, by the concentration of elites in continuous conflicts and the lack of noticeable progress in the implementation of declared reforms.

The third phase (revival) provides the stabilization at somewhat higher level than observed at the depression phase; final disappointment of the civil society is observed in view of adjusting the convergent model of the interaction with the state, particularly, at axiological and teleological levels. The state and civil society concentrate on their own objectives and reduce the productive interaction to minimum required one. The first wave of divergence is formed in a new cycle as the interaction of a civil society and the state.

The forth phase (growth phase) combines two contradictive tendencies: on the one hand, the development of an active confrontation of a civil society and the state as a logical consequence of strengthening the divergence processes between them and, on the other hand, a noticeable economic growth that mainly occurs at the expense of a favourable situation in the world markets for basic items of the Ukrainian export or direct external macro-financial assistance (by IMF etc).

Thus, the "anatomy" of Ukrainian crisis is reduced to the following. Typical linear models of social transformation declared are not implemented as a result of the fact that they do not correspond to the hybrid form of the interaction between a weak civil society and non-effective and corrupt bodies of public administration characteristic of Ukraine and do not provide the strategy aiming at the rooting away or at least minimizing basic prerequisites for a cyclic recurrent crisis. A weak natural impulse to the convergence between the civil society and the state rapidly becomes extinct because it is impossible to provide immediate positive changes that the society as a whole anticipates in conditions described above; the divergent processes (institutional, axiological, instrumental ones etc.) 
enhance as a result of the previous ineffective approximation. The accumulation of "critical mass" of these phenomena results in teleological divergence leads to loss of feeling of the necessity to interact for the sake of reaching a common goal, it provokes the state to "absorb" the civil society under the renewal of archaic authoritarian concept of "a strong power" and it finally determines their open confrontation. The solution of the latter becomes possible only in terms of a system social crisis.

\section{Conclusions}

The understanding of the above stated issues makes it possible to come to a number of logical conclusions.

Concepts of historical recurrence are characteristic of the history of the philosophical and synergetic thought development (particularly, for some of its stages) and of a wide range of social sciences. Their origination is primarily associated with tracing for the recurrences and related phenomena and processes in a complex multifold social life, with thinkers and researches' willing not only state the dynamics of their development outlining successive phases in the structure of their transformation that usually develop into one another, but also to apply the methods of quantitative computations to the accumulated data, as well as to make an attempt to give substantiated forecast on a basis of the results received. Very soon the abstract philosophical concepts were used for the analysis of recurrences in political life; some concepts of successive recurrence of the forms of government were stated as far back as in the in antiquity and recommendations to minimize negative phenomena related to the political recurrence were proposed.

Negative aspects of recurrent transformations were evident even for ancient thinkers. Rigorous recurrent models used by them firstly provided a well-defined change of political orders, the alteration of "true" and "perverted" forms of government, phases of degradation and growth of political life, "closed" in continuous succession of events that did not provide significant development; the possibility to go out of a cycle was actually possible in applying a specific hybrid form of government deprived of shortcomings intrinsic to "ordinary" forms. Modern concepts of recurrence (mainly, within the framework of economic and political sciences) do not apply rigid models concentrating mainly on the forecast of the recurrent crisis, minimizing its negative consequences and in strategies of influence on its prerequisites.

After a break in the 19th century related to spreading the theory of linear development, the first-half of the 20th century is distinguished by the significant growth of scholarly interest to the subject-matter of the problem in view of conceptually new researches of the fundamental character, in particular, M. Kondratiev's theory of "long waves" in the world economy; J. Schumpeter's concepts of economic cycles and P. Sorokin's sociological researches. Modern social sciences outlined the tendency to carry out interdisciplinary researches. The problem of meeting cyclical social crises characteristic of transitive societies is considered one of the current tendencies. The results obtained may be successfully 
used within the framework of public administration as a science wherein there was a lack of subject-matter researches of a monographic level.

For the recurrent crisis in Ukraine mostly predetermined by the disability to implement a convergent model of the interaction between bodies of public administration and the civil society (situation we describe as hybrid democracy), it is impossible to solve this problem only at the expense of reforms of a public administration (even successful ones) or by fostering the development of the civil society. Deliberate attempts are required to implement a convergent form of the interaction between the civil society and the state at all its levels: teleological, institutional, axiological, instrumental ones etc.

Attempts to impose the absolute linear model of development (often reduced to the perception of common values and joining a definite political community) on a polarized society immanently liable to "pendular" oscillations only make the situation worse. Strategies of social transformations in Ukraine should take into account the recurrent character of the interaction between bodies of public administration and the civil society and provide minimization of negative consequences of cyclic recurrent crisis in the first place. The development of such strategies is possible especially under the public administration studies.

Modern civil service in Ukraine is conceptually represented as a parti-coloured hybrid of the soviet bureaucracy relics, models borrowed from stable convergent societies (EU and USA) and the results of mainly intuitive adjustment to a complex political life. None of these components provides an effective response to the recurrent crisis that is specific for a hybrid form of the interaction between the state and the civil society. Meanwhile, a civil service within Ukrainian conditions should be one the significant levers of a positive influence on preconditions for the origin and recurrence of a cyclical crisis or, at least, to be a tool minimizing its negative consequences.

\section{References}

[1] Akaev et al. (2012), Kondratevskie volnyi. Aspektyi i perspektivyi [Kondratiev's waves. Aspects and prospects], (Volgograd: «Uchitel»), 384 pp.

[2] O. Aleynikova (2014), Theories of recurrence and problems of structural, financial and system crises of public production, Ekonomika. Upravlinnya. Innovatsiyi, vol 1 (11),

[3] http://nbuv.gov.ua/j-pdf/eui_2014_1_3.pdf

[4] Aristotle (1976), Metafizika [Metaphysics], vol 1 (Moscow: «Myisl»), 550 pp.

[5] V. Bazilevich et al. (2006), Istoriya ekonomichnih uchen [Hystory of economical studies], vol. 2 (Kyiv: «Znannya»), 575 pp.

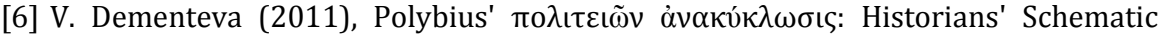
Analysis, Realnost. Retrospektsiya. Rekonstruktsiya: Problemyi vsemirnoy istorii, pp. 3-9, http://elar.uniyar.ac.ru/jspui/handle/ 123456789/1951

[7] F. Klinberg (1983), Cyclical Trends in "American Foreign Policy Moods", (Lanham, Md.: University. Press of America), $208 \mathrm{pp}$.

[8] F. Klinberg (1952), The Historical Alternation of Moods, American Foreign Policy in World politics, vol. 4, pp. 239-273. 
[9] Korotaev et al. (2009), Kondratevskie volnyi v mirovoy ekonomicheskoy dinamike [Kondratiev's waves in world economic dynamics] in Sistemnyiy monitoring. Globalnoe i regionalnoe razvitie, (Moscow: Librokom/URSS), pp. 189-229.

[10]V. Limonov (2011), Recurrence of historical process in sociology and philosophy of XX century, Vestnik MGUKI, 3 (41), pp. 58-64.

[11]N. Machiavelli (1982), Izbrannyie sochineniya [Selected works], (Moscow: «Hudozhestvennaya literatura»), $514 \mathrm{pp}$.

[12]N. Machiavelli (1987), Istoriya Florentsii [History of Slorence], (Moscow: «Nauka»), 449 pp.

[13]Medushevskiy (2005), Teoriya konstitutsionnyih tsiklov [Theory of constitutional cycles] (Moscow: Izd. Dom GU VShE), 574 pp.

[14]S. Menshikov et al. (1989), Dlinnyie volnyi v ekonomike. Kogda obschestvo menyaet kozhu [Long waves in an economy], (Moscow: «Mezhdunarodnyie otnosheniya»), $274 \mathrm{p}$.

[15]D. Modelski (1992), Kondratiev's waves, development of world economic and international politics, Voprosyi ekonomiki, vol 10, pp. 49-57.

[16]J. Namenwirth et al. (1987), Dynamics of Culture (Winchester: Alien and Unwin), $268 \mathrm{p}$.

[17]Novaya filosofskaya entsiklopediya [New philosophical encyclopedia] (2010), (Moscow: «Myisl»),

[18] http://iph.ras.ru/elib/3359.html

[19]0. Onufrienko (2000), Algorithmical nature of law norms and legal acts: experience of searching for analogies, Ukrayinske pravo, 1, pp.152-159.

[20]0. Onufrienko (2015), Dialectics of interaction of the state and institutes of civil

[21] society in context of theory of public administration, Publichne administruvannya: teoriya i praktika, (Dnipropetrovsk: DRIDU NADU), 1 (13),

[22]http://www.dbuapa.dp.ua/zbirnik/2015-01(13)/index.html

[23]Plato (1972), Sochineniya $\mathrm{v}$ tryoh tomah [Works in three volumes], (Moscow: «Myisl»), T. 3, Ch. 2, 678 pp.

[24]Y. Plotinskiy (2001), Modeli sotsialnyih protsessov [Models of social process] (Moscow: «Logos»), $280 \mathrm{pp}$.

[25]Poletaev et al. (1993), Tsiklyi Kondrateva i razvitie kapitalizma: (opyit mezhdistsiplinarnogo issledovaniya) (Moscow: «Nauka»), $249 \mathrm{p}$.

[26]0. Puhkal (2011), Modernizatsiya sistemi derzhavnogo upravlinnya v konteksti rozvitku gromadyanskogo suspilstva v Ukrayini (Kyiv), 36 pp.

[27]P. Sorokin (1998), Obzor tsiklicheskih kontseptsiy sotsialno-istoricheskogo protsessa in Sotsiologicheskie issledovaniya, 12, pp. 3-14.

[28]P. Sorokin (2000), Sotsialnaya i kulturnaya dinamika: Issledovanie izmeneniy v bolshih sistemah iskusstva, istinyi, etiki, prava i obschestvennyih otnosheniy (SaintPetersburg: RHGI), 1056 pp.

[29]D. Vico (1994), Osnovaniya novoy nauki ob obschey prirode natsiy (Moscow-Kyiv: «REFL book» «ISA»), $656 \mathrm{p}$. 